\title{
Econometric analysis of technical efficiency of pearl millet farmers in Kano State, Nigeria
}

\author{
Umar Mukhtar ${ }^{1 \& 2^{*}}$, Zainalabidin Mohamed $^{1}$, Mad Nasir Shamsuddin ${ }^{1}$, Juwaidah \\ Sharifuddin ${ }^{1}$, and Muhammad Bala ${ }^{1 \& 3}$ \\ ${ }^{1}$ Department of Agribusiness and Bioresource Economics, Faculty of Agriculture, Universiti Putra \\ Malaysia, 43400 UPM Serdang, Selangor Darul Ehsan, Malaysia \\ ${ }^{2}$ Department of Agricultural Economics and Extension, Faculty of Agriculture, Federal University \\ Dutse, P.M.B. 7156, off- Ibrahim Aliyu Bye-Pass, Jigawa State-Nigeria \\ ${ }^{3}$ Department of Agricultural Economics and Extension, Faculty of Agriculture, Taraba State \\ University, Jalingo-Nigeria.
}

\begin{abstract}
In Nigeria, particularly the northern parts, pearl millet is a traditional crop that is very important to nation's food security. Empirical evidence indicates that the main problem in pearl millet production in Nigeria is associated with low productivity and inefficiency in allocation of resources. This study therefore sought to analyse the Technical Efficiency (TE) of pearl millet farmers in Kano State of Nigeria, being the state with highest concentration of pearl millet farmers. SFA approach is used on a data collected from 256 randomly sampled pearl millet farmers during 2013/2014 cropping season. The study discovers that all the production inputs/variables included in the Cobb-Douglas Stochastic Frontier function with exception of agrochemicals were positively and significantly associated with TE. The TE range of $21 \%$ to $94 \%$ and mean TE of $73 \%$ were obtained from the analysis. The study also reveals that access to credit, education, extension and household size were the major contributors to TE. This therefore calls for formulation of appropriate policy that would extend these key determinants of TE which would go a long way in improving farmers' efficiency level and economic benefits. This study contributes the first SFA approach in estimating TE of pearl millet farmers in Kano State, Nigeria, which can effectively help in addressing food insecurity problem in the country.
\end{abstract}

\section{Introduction}

Pearl millet is grass in the family of Panacea that originated from western tropical Africa about 3,000 years ago. It spreads throughout eastern and southern Africa, also some parts of America and Australia. According to [1], pearl millet, the sixth most important cereal crop in the world, providing sustenance to about 500 million masses in the arid and semi-arid, predominantly in Asia and Africa.

Nigeria was once the second world largest millet producer after India, where it is widely grown for its grain to make flour and other materials. In Nigeria, especially in the northern

*Correspondence: umarmukhtar79@gmail.com 
parts pearl millet is one of the most important staple crops both in terms of production and c onsumption, and it is considered as staple food crop for over $40 \%$ of the populace. However , performance of pearl millet among smallholder farmers has either stagnated or progressed at a very slow pace, placing the average yield for this vital crop at 1-1.5 $\mathrm{t} / \mathrm{ha}$ as against the potential yields of 2.5-4t/ha [2,3]. Although a lot of efforts were made by both governments and non-governmental organizations to improve the productivity of pearl millet in the country through introduction of improved varieties and associated technologies, but the yields realize by resident farmers is still far below the average potential yield. This positions the country's yield at $30^{\text {th }}$ in the world ranking [3].

This low productivity can be ascribed to inefficiency among farmers, which usually caused by poor understanding of efficient agricultural practices and inappropriate inputs combination. It is asserted that gap between actual yield realized on farmers' fields and the potential farm yield is largely attributed to management practices, which depend on socioeconomic characteristics of farmers [4]. This means that agricultural performance is not only a function of the productivity of technical inputs, but increased yield is also directly associated with socioeconomic factors of the farmers. As productivity and output are positively related to efficiency, it is imperative to estimate the TE levels and to also determine the socioeconomic factors responsible for these TE levels among pearl millet farmers in the study area which this study is set to achieve.

\section{Materials and Methods}

The sampling frame of the study is pearl millet farmers in Kano State of northern Nigeria. Structured questionnaire was used as a research instrument to collect the data from 256 randomly selected pearl millet farmers in the study area. Stochastic Frontier Analysis (SFA) was used during 2013/2014 cropping season.

\section{Empirical Model}

The Stochastic Frontier Analysis (SFA) was used to analyze the technical efficiency of pearl millet farmers. The stochastic frontier production function to measure the technical efficiency of production was independently developed by $[5,6]$. The Stochastic Frontier Production Function is more appropriate for measuring technical efficiency because it overcomes the inadequate characteristics of the assumed error term in traditional (conventional) production functions which have limitations on statistical inference of the parameters and the resulting efficiency estimates.

The production technology of the pearl millet farmers in Kano State, Nigeria was assumed to be specified by the Cobb-Douglas frontier production function. This according to $[7,8]$ has been used by many empirical studies, particularly those relating to agriculture in developing countries. The Cobb-Douglass frontier production function of the model in mathematical form can be specified as follows:

$$
\ln Y_{i}=\beta_{0}+\beta_{1} \ln X_{1 i}+\beta_{2} \ln X_{2 i}+\beta_{3} X \ln _{3 i}+\beta_{4} \ln X_{4} i+\beta_{5} \ln X_{5 i}+\beta_{6} \ln X_{6 i}+v_{i}-u_{i}
$$

Where:

$\ln =$ the natural logarithm

$\mathrm{Y}_{\mathrm{i}}=$ Quantity of Pearl millet output $(\mathrm{kg})$

$\mathrm{X}_{1}=$ Farm Size (hectares)

$\mathrm{X}_{2}=$ Fertilizer $(\mathrm{Kg})$

$\mathrm{X}_{3}=$ Manure (ox-cart)

$\mathrm{X}_{4}=$ Labour (man-days) 
$\mathrm{X}_{5}=$ Seeds $(\mathrm{kg})$

$\mathrm{X}_{6}=$ Agrochemicals (litres)

$\beta_{0}=$ Intercept

$\beta_{1}-\beta_{6}=$ Parameters to be estimated

$\mathrm{i}=$ number of farm

$\mathrm{V}_{\mathrm{i}}=$ Stochastic component of error term beyond the control of farmers

$\mathrm{U}_{\mathrm{i}}=$ non-negative random variables assumed to account for technical inefficiency in production process.

\section{The farm specific inefficiency variables}

The technical inefficiency model was used to identify factors that influence the efficiency among pearl millet farmers in the study area, and based on [9]. the model was specified as follows:

$$
\begin{aligned}
U_{i} & =\propto_{0}+\propto_{1} Z_{1 i}+\propto_{2} Z_{2 i}+\propto_{3} Z_{3 i}+\propto_{4} Z_{4 i}+\propto_{5} Z_{5 i}+\propto_{6} Z_{6 i}+\propto_{7} Z_{7 i} \\
& +E_{i}
\end{aligned}
$$

Where:

$\mathrm{U}_{\mathrm{i}}=$ technical inefficiency

$\mathrm{Z}_{1}=$ Age (years)

$Z_{2}=$ Level of Education (years)

$\mathrm{Z}_{3}=$ Farming experience (years)

$\mathrm{Z}_{4}=$ Cooperative membership $(1=$ member, $0=$ otherwise $)$

$\mathrm{Z}_{5}=$ Access to credit $(1=$ access, $0=$ otherwise $)$

$\mathrm{Z}_{6}=$ Household size (number)

$\mathrm{Z}_{7}=$ Extension contact $(1=$ access to extension, $0=$ otherwise $)$

$\alpha_{1}-\alpha_{7}=$ scalar parameters to be estimated

$\alpha_{\mathrm{o}}=$ constant or intercept

$\mathrm{E}_{\mathrm{i}}=$ stands for the random variables defined by the truncation of the normal distribution with mean 0 and variance, $\sigma_{u}^{2}$, such that the point of truncation is $-Z_{i} \propto$, i.e. $\mathrm{E}_{\mathrm{i}} \geq-Z_{i} \propto$. These assumptions are consistent with $\mathrm{U}_{\mathrm{i}}$ being a non-negative truncation of the $\left(Z_{i} \propto, \sigma_{u}^{2}\right)$ distribution [9].

\section{Results and discussion}

The frequency distribution of the stochastic production frontier model is shown in Table 1 .

Table 1 Technical Efficiency Distribution of Pearl Millet Farmers for Kano State

\begin{tabular}{|l|c|c|}
\hline Technical Efficiency & Number of Farmers & Percentage \\
\hline $0.21-0.30$ & 9 & 3.52 \\
\hline $0.31-0.40$ & 12 & 4.69 \\
\hline $0.41-0.50$ & 17 & 6.64 \\
\hline $0.51-0.60$ & 16 & 6.25 \\
\hline $0.61-0.70$ & 40 & 15.63 \\
\hline $0.71-0.80$ & 57 & 22.26 \\
\hline $0.81-0.90$ & 53 & 20.70 \\
\hline
\end{tabular}




\begin{tabular}{|l|c|c|}
\hline $0.91-0.99$ & \multicolumn{1}{|c|}{52} & 20.31 \\
\hline Total & \multicolumn{1}{|c|}{$\mathbf{2 5 6}$} & $\mathbf{1 0 0 . 0 0}$ \\
\hline Minimum TE & $\mathbf{0 . 2 1}$ & \\
\hline Mean TE & $\mathbf{0 . 7 3}$ & \\
\hline Maximum TE & $\mathbf{0 . 9 4}$ & \\
\hline
\end{tabular}

Results of the analysis reveal that TE of pearl millet production in the study area ranged from a minimum of $21 \%$ to a maximum of $94 \%$, with an average of $73 \%$.

The results further indicate that for the average farmer in the sample to attain the TE of his/her most efficient peers, he/she could achieve about $22.34 \%\{1-(73 / 94) \times 100\}$ cost savings. Similarly, the least technically efficient farmer will have $77.66 \%\{1-(21 / 94) \mathrm{x}$ $100\}$ cost savings to become the most efficient farmer.

\section{Maximum likelihood estimates (MLE) of the parameters of the stochastic frontier function}

The result of the maximum likelihood estimates of the Stochastic Frontier of pearl millet production function is presented in Table 2. The sigma-square was $0.155(\mathrm{p}<0.01)$, confirming the good fit of the model and the correctness of the distributional form assumed for the composite error term. The value of gamma $(\gamma)$ was 0.818 and was statistically significant at $1 \%$, implying that $82 \%$ of the variation in pearl millet output of the farmers was due to technical inefficiency term $\left(\mathrm{u}_{\mathrm{i}}\right)$ rather than random error $\left(\mathrm{v}_{\mathrm{i}}\right)$ associated with uncontrollable factors which affect production. This explains why ordinary least squares (OLS) or an average production function was not a suitable specification for sampled pearl millet farmers.

Table 2 Maximum likelihood estimates of the parameters of the stochastic frontier function

\begin{tabular}{|l|l|l|l|}
\hline Variables & Coefficient & std-error & t-ratio \\
\hline Constant & 1.879 & 0.852 & $2.205^{* *}$ \\
\hline LnFarmsize & 0.232 & 0.051 & $4.549^{* * *}$ \\
\hline LnFertilizer & 0.391 & 0.166 & $2.355^{* *}$ \\
\hline LnManure & 0.184 & 0.092 & $2.000^{* *}$ \\
\hline LnLabour & 0.526 & 0.105 & $5.010^{* * *}$ \\
\hline LnSeed & 0.243 & 0.054 & $4.500^{* * *}$ \\
\hline LnAgrochemicals & -0.428 & 1.262 & $-0.339^{\text {NS }}$ \\
\hline Inefficiency Effects & & & \\
\hline Age & 0.7746 & 0.2634 & $2.294^{* *}$ \\
\hline Level of education & -0.1449 & 0.0268 & $-5.408^{* * *}$ \\
\hline Farming experience & 0.2556 & 0.5632 & $0.454^{\text {NS }}$ \\
\hline Coopt. Membership & 0.8428 & 0.3936 & $2.141^{* *}$ \\
\hline Access to credit & -0.1485 & 0.0387 & $-3.834^{* * *}$ \\
\hline Household size & -0.8606 & 0.4552 & $-1.89^{*}$ \\
\hline Extension Contact & -0.2372 & 0.4289 & $-5.531^{* * *}$ \\
\hline Diagnostic Statistics & & & \\
\hline sigma-squared $\left(\delta^{2}\right)$ & & & $3.690^{* * *}$ \\
\hline
\end{tabular}




\begin{tabular}{|l|l|l|l|}
\hline Variables & Coefficient & std-error & t-ratio \\
\hline gamma $(\mathrm{y})$ & 0.818 & 0.124 & $6.597 * *$ \\
\hline Log-likelihood Function & 7.848 & & \\
\hline $\begin{array}{l}\text { Note: NS=Not Significant. } \\
\begin{array}{l}* * *, * * \\
\text { respectively. }\end{array}\end{array}$
\end{tabular}

The estimated coefficient for farm size $(0.232)$ was positive and statistically significant at $1 \%$. This implies that a $1 \%$ increase in farm size will ceteris paribus lead to an increase of $0.232 \%$ in output. This increase is inelastic because a $1 \%$ increase in the input leads to a less than $1 \%$ increases in the output. This result is not at variance with those obtained by [10] and [11].

The production elasticity of output with respect to a quantity of fertilizer (0.391) was positive and statistically significant at $1 \%$ level. This implies that a $1 \%$ increase in the amount of fertilizer applied on the farm will increase output by $0.391 \%$ ceteris paribus. Similar results were found by [12] and [13].

The estimated coefficient for manure was positive and significant at $1 \%$ which implies increased output, because as the quantity of manure increase by $1 \%$, the yield will also increase by $0.184 \%$, ceteris paribus. This result is in tandem with the one obtained by [14] who found animal manure to have a positive and significant effect on TE among Banana farmers in Uganda. It is also in conformity with [13] and [15].

The estimated coefficient for labour (persons in man-days) was positive and statistically significant at $1 \%$. This implies that increasing labour by $1 \%$ will increase output by about $0.526 \%$ ceteris paribus. The findings correspond to those obtained by [10] and [16] but are not in accordance with findings of [17] and [18]

The estimate for seed $(0.243)$ is positive and significant at $5 \%$. The significance of seed quantity is due to the fact that seed determines to a large extent the output obtained. Output tends to be low even when other inputs are in abundance if quality seeds and accurate seed rates are not used. . The result was again indistinguishable to that of [19] and [20].

\section{Factors Explaining Inefficiency}

The parameters of the explanatory variables in the inefficiency model were simultaneously estimated in a single stage using a computer program, FRONTIER 4.1. Since the dependent variable of the function stands for inefficiency, the sign of the coefficients of these variables has important policy implications as the positive sign indicates a negative effect on technical efficiency whereas negative sign signifies a positive effect on efficiency. The results of the inefficiency effects model are also shown in Table 2.

The positive sign of farmers' age show that TE decreases with age of pearl millet farmers and is significant at 5\% level of probability. This implies that aged farmers were less technically efficient in pearl millet production Kano State. This may be due to the fact that younger pearl millet farmers adaptive to modern and improved technologies of farm production and management which result in increased farm efficiency. In contrary, aged farmers are often reluctant to try new farm technologies and mostly stick to traditional and conservative farming techniques which are usually associated with inefficiency.

The coefficient of cooperative membership indicates unexpected sign, it has significant positive effect on the technical inefficiency of pearl millet farmers. This implies that farmers who did not belong to any cooperative society are more technically efficient. It is agreed that the key impetus of farmers in cooperative societies is to access vital information and farm inputs at a subsidized rate for improved productivity. This can be attributed to the fact that pearl millet farmers in the study area never actively participated in the activities of 
cooperative societies which contributed to the inability to improve their knowledge and skills in crop production management.

The coefficient of education is negative and significant at $1 \%$, suggesting that investment in human capital is a strong device to improve technical efficiency in pearl millet production in the study area. The result further signifies that smallholder pearl millet farmers that have acquired education at a certain level would be more technically efficient than those that have not. The reason might be that such farmers would more likely follow and apply the recommended principles underlying the use of improved technology at their farms and result in efficient resource use.

The coefficient of extension contact was found to be significant and negative, whose implication is that increased contacts with extension officers decrease technical inefficiency. This implies that easy access to extension contact would also expose the pearl millet farmers in the study area to some modern farming techniques that assure higher yield and productivity.

The coefficient of access to credit is significant and negatively associated with technical inefficiency. That is, increased access to credit increases technical efficiency level of the pearl millet farmers. An assertion by [21] also explains that farm credit boosts diversification of agricultural systems that stabilize and possibly improve farm productivity, if it is appropriately extended, managed and utilized.

The household size variable is negatively related to technical inefficiency, but weakly significant only at $10 \%$. This means farmers with large family size are less technically inefficient. This is probably because farmers that have large household size tend to endeavour to obtain higher output in order to meet their subsistence necessities. Furthermore, large household size has labour endowment required to implement farm management decisions.

\section{Comparison of the Efficient, Average and Least Efficient Farmers in Terms of Inputs used Per Hectare}

Optimum use for each input per hectare at farm level and its optimum score are reported in Table 3. The quantities of inputs used by the most technically efficient farmers in the sample to produce an average output of $1372.85 \mathrm{~kg} / \mathrm{ha}$ were fertilizer $(82.78 \mathrm{~kg} / \mathrm{ha})$, manure (15.76 ox-cart/ha), labour (34 Man-days/ha), seed (28.00 kg/ha) and agrochemicals (1.35 litre/ha). In contrast, an average efficient farmer in the sample used fertilizer $(83.37 \mathrm{Kg} / \mathrm{ha})$, manure (13.60 ox cart/ha), labour (33 man days/ha), seed (31. $40 \mathrm{~kg} / \mathrm{ha})$ and agrochemicals (1.09 litre/ha) to produce $1123.12 \mathrm{~kg} /$ ha of output. Similarly, the least technically efficient farmer in the sample made use of fertilizer $(74.23 \mathrm{Kg} / \mathrm{ha})$, manure $(18.85 \mathrm{ox} \mathrm{cart} / \mathrm{ha})$, labour (33 man days/ha), seed (20. $77 \mathrm{~kg} / \mathrm{ha})$ and agrochemicals (1.54 litre/ha) to cultivate an average pearl millet output of $1120.67 \mathrm{~kg} / \mathrm{ha}$. These results imply that fertilizer, seed, and agrochemicals were over-utilized, while labour and manure were over-utilized by the average technically efficient farmer in the sample. Therefore, for the average technically efficient farmer to attain optimality, they should reduce the use of fertilizer, seed and agrochemicals by $0.59 \mathrm{~kg} / \mathrm{ha}(0.67 \%), 3.40 \mathrm{~kg} / \mathrm{ha}(10.83 \%)$ and 0.26 litre $(23.85)$ from the current levels, respectively. However, since manure and labour were underused, their use should be increased by 2.16 ox-cart/ha $(15.88 \%), 1$ man-days $(3.03 \%)$ to ensure efficient pearl millet production.

In the same way, when compared to the most technically efficient farmer, the least technically efficient farmer in the group under-utilized the application of fertilizer, labour, and seed. So, since the utilization of these inputs has not reached the optimum level as used by the most technically efficient farmers for optimal resource allocation in pearl millet production, it is necessary to increase their consumption by $8.55 \mathrm{~kg} / \mathrm{ha}(11.52 \%), 1 \mathrm{man}-$ 
days/ha (3.97\%) and $7.23 \mathrm{~kg} / \mathrm{ha}(34.81 \%)$ from the levels currently used by farmers, respectively. However, the least efficient farmers should reduce the use of manure and agrochemicals by 3.09 ox-cart/ha (16.39\%) and 0. 19litre (12.34), respectively, since the use of these particular inputs were found to be greater than their optimum levels compared to the most efficient farmer. The findings are somehow similar to results reported by Coelli et al., (2002) [22] where fertilizer and labour were found to be highly overutilized by rice farmers in Bangladesh. 


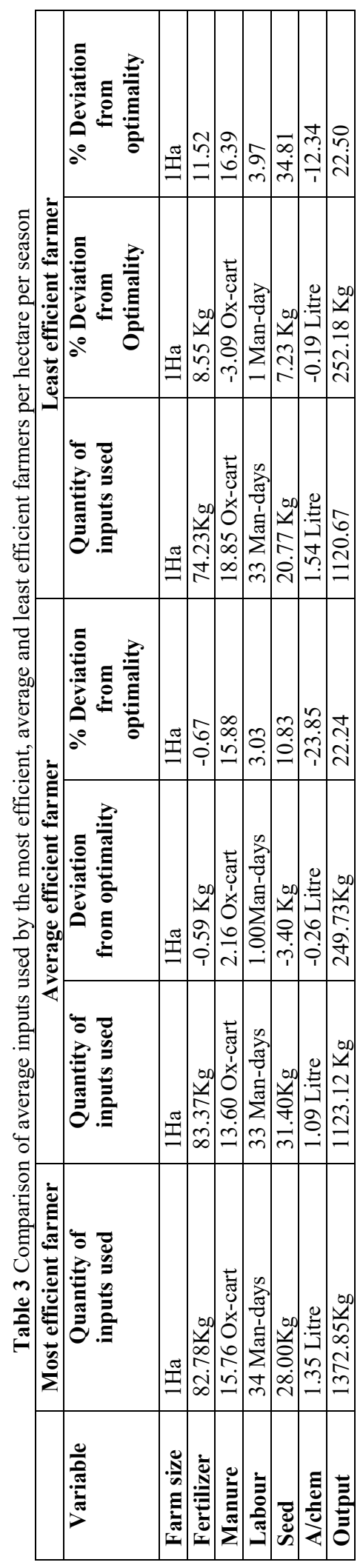




\section{Conclusions Policy Implications}

The study revealed that the farmers were, on average, $73 \%$ efficient, which implies the existence of potentials improve TE in pearl millet production in the area. The above figure also implies that cultivating at about $27 \%$ further down the frontier level. This is an evidence that farmers in the study area do not have much score (little scope) to expand the productivity of pearl millet through efficiency under the current conditions of resource use and technology at the farm level. The study further discovered that educational level, extension contact, credit access and household size were found to be the main factors directly associated with TE of pearl millet farmers, while the age of farmers and cooperative membership were inversely related to TE. The study concludes that pearl millet farmers have abundant potential to enhance their production through improving available resources at their disposal. There were also both underutilization and overutilization of resources. The findings are also of paramount importance as they provide detailed and vital information to policy makers on nature of production techniques employed in pearl millet in the area. Hence, since the sources of inefficiency are identified, policy formulations to improve farmers' performance can be effectively done.

\section{References}

1. A.G. Gaya, S.A. Adebitan, and A.U. Gurama, Reaction of Pearl Millet Infected with Downy Mildew (Sclerospora Graminicola (Sacc.) Schroet) Intercropped Cowpea with On Days to 50\% Heading and Grain Yield in The Savanna Zone of Northern Nigeria. Bay. J. Pure \& Appl. Sci. 5, 1- 4 (2012).

2. B.G. Soulé, D. Balami, and R. Blein, Framework for involvement in rainfed food cro p supply chains development in West and Central Africa: Nigeria's Cereal Economy, AFD, CIRAD, IFAD, July (2010).

3. FAO, http://faostat3.fao.org/home/index retrivied : December 20, 2015)

4. E.O. Onyuka, J. Kibbet, and C.O. Gor, Socio-Economic Determinants of Groundnut Production in Ndhiwa Sub-County, Kenya. Int. J. Agric. \& F. Res. 6, 1-14 (2017).

5. D. Aigner, C.K. Lovell, and P. Schmidt, Formulation and estimation of stochastic frontier production function models. J. Econ. .6, 21-37 (1977).

6. W. Meeusen, and J. van Den Broeck, Efficiency estimation from Cobb-Douglas production functions with composed error. Int. econ. rev. 18, 435-444 (1977).

7. P.T. Tsue, W.L. Lawal, and V.O. Ayuba, Productivity and Technical Efficiency of Catfish Farmers in Benue State, Nigeria. Adv. J. Agric. Res. 1, 20-25 (2013).

8. K. Ogundari, S.O. Ojo and B. Brummer, Productivity potential and technical efficiency of aquaculture production in alleviating poverty: Empirical Evidence from Nigeria. J, Fish. Int. 1, 21-26 (2006).

9. G.E. Battese, and T.J. Coelli, A model for technical inefficiency effects in a stochastic frontier production function for panel data. Emp. econ. 20, 325-332 (1995).

10. B.E. Bravo-Ureta, and A.E. Pinheiro, Technical, Economic and Allocative Efficiency in Peasant Farming; Evidence from Dominican Republic. The Dev. Econ.. 35, 48-67 (1997).

11. S.B. Wassie, Technical efficiency of major crops in Ethiopia: stochastic frontier model. Acad. J. Agric. Res. 2, 147-153 (2014).

12. A. Ali, and A.U. Jan, Analysis of technical efficiency of sugarcane crop in Khyber Pakhtunkhwa: A stochastic frontier approach. Sarhad J. Agric. 33, 69-79 (2017). 
13. W. Alwarritzi, T. Nanseki, and Y. Chomei, Analysis of the factors influencing the technical efficiency among oil palm smallholder farmers in Indonesia. Proce. Env. Sci. 28, 630-638 (2015).

14. F. Bagamba, F.R. Ruben, and M. Rufino, Determinants of banana productivity and technical efficiency in Uganda. An economic assessment of banana genetic improvement and innovation in the Lake Victoria Region of Uganda and Tanzania: Vol. 155, 109 (2007).

15. K.M.M. Rahman,M.I.A. Mia and M.K.J.A. Bhuiyan, stochastic frontier approach to model technical efficiency of rice farmers in Bangladesh: An empirical analysis. The Agriculturists, 10, 9-19 (2012).

16. Ng'ombe, and T. Kalinda, A Stochastic Frontier Analysis of Technical Efficiency of Maize Production Under Minimum Tillage in Zambia. Sust. Agric. Res. 4, 31-46 (2015).

17. G.M. Kitila, and B.A. Alemu, Analysis of Technical Efficiency of Small Holder Maize Growing Farmers of Horo Guduru Wollega Zone, Ethiopia: A Stochastic Frontier Approach. Sci. Tech. \& Arts Res. J. 3, 204-212 (2014).

18. D.K. Mugambi, M. Mwangi, S.K. Wambugu, and A.M. Gitunu, Assessment of performance of smallholder dairy farms in Kenya: an econometric approach. J. Appl. Biosci. 85, 7891-7899 (2015).

19. D. Awunyo-Vitor, J. Bakang, and S. Cofie, Estimation of farm level technical efficiency of small-scale cowpea production in Ghana. Amer-Eur. J. of Agric. \& Env. Sci. 13, 1080-1087. (2013).

20. M.H. Ahmed, Z. Lemma and G. Endrias Measuring Technical, Economic and Allocative Efficiency of Maize Production in Subsistence Farming: Evidence from The Central Rift Valley of Ethiopia. Appl. Std. in Agrib. Comr. 9, 63-74 (2015).

21. B.M. Desai, and J.W. Mellor, Institutional Finance for Agricultural Development: An Analytical Survey of Critical Issues, Food. Pol. Rev .1, (1993)

22. T. Coelli, S. Rahman and C. Thirtle, Technical, Allocative, Cost and Scale Efficiencies in Bangladesh Rice Cultivation: A Non-parametric Approach. J. Agric. Econ. 53, No. 3: p607-626 (2002). 